\title{
25 Research Soure \\ Effects of Tool Wear on Machined Surface Integrity During Milling of Inconel 718
}

\author{
Liang Tan ( $\nabla$ tanliang@mail.nwpu.edu.cn ) \\ Northwestern Polytechnical University \\ Changfeng Yao \\ Northwestern Polytechnical University \\ Dinghua Zhang \\ Northwestern Polytechnical University \\ Minchao Cui \\ Northwestern Polytechnical University \\ Xuehong Shen \\ Northwestern Polytechnical University
}

\section{Research Article}

Keywords: Inconel 718, Tool flank wear, Surface roughness, Residual stress, Microhardness, Microstructure

Posted Date: March 26th, 2021

DOl: https://doi.org/10.21203/rs.3.rs-349683/v1

License: (c) (i) This work is licensed under a Creative Commons Attribution 4.0 International License. Read Full License

Version of Record: A version of this preprint was published at The International Journal of Advanced Manufacturing Technology on July 9th, 2021. See the published version at https://doi.org/10.1007/s00170-021-07626-x. 


\section{Abstract}

This paper investigates the effects of tool wear on the machined surface integrity characteristics, including the surface roughness, surface topography, residual stress, microhardness and microstructure, during ball-end milling of Inconel 718. Tool wear, tool lifetime, and cutting force are measured. In addition, a two-dimensional finite element-based model is developed to investigate the cutting temperature distribution in the chip-tool-workpiece contact area. Results show that the ball nose end mill achieves tool lifetime of approximately $350 \mathrm{~min}$. The cutting forces increase sharply with a greater tool flank wear width, while the highest cutting temperature has a decreasing tend at a flank wear width of $0.3 \mathrm{~mm}$. Higher tool flank wear width produces larger surface roughness and deteriorative surface topography. A high-amplitude (approximately -700 MPa) and deep layer (approximately $120 \mathrm{~mm}$ ) of compressive residual stress are induced by a worn tool with $0.3 \mathrm{~mm}$ flank wear width. The surface microhardness induced by new tool is larger than that induced by worn tool. Plastic deformation and strain streamlines are observed within $10 \mathrm{~mm}$ depth beneath the surface. The results in this paper provide an optimal tool wear criterion which integrates the surface integrity requirements and the tool lifetime for ball-end finish milling of Inconel 718.

\section{Introduction}

Nickel-based superalloys are widely applied in aero-engine key components because of their excellent chemical and mechanical properties at elevated temperatures [1]. Inconel 718, the most popular nickelbased superalloy, is usually used in manufacturing the hot sections of aero-engines, especially for turbine discs because of its superior strength at around $650^{\circ} \mathrm{C}$. However, it is also regarded as one of the most difficult-to-cut materials due to its low thermal conductivity and high-temperature strength and hardness $[2,3]$. When machining Inconel 718, severe work hardening, high cutting forces and temperatures often occur [4]. Besides, welding and adhesion between the alloy and tool material further exacerbate machining difficulties $[5,6]$. As a result, cutting tools wear rapidly, which affects and damages the machined surface integrity characteristics, including external topographical parameters, mechanical properties, and metallurgical states.

Various works have focus on investigating the effects of cutting parameters and tool wear on the machined surface integrity of nickel-based superalloys. Several articles reviewed and summarized the recent advances of surface integrity in machining of titanium and nickel alloys [7-9]. It is well known that the alteration of surface integrity is associated with the coupled thermo-mechanical effects, which is affected by the cutting parameters, tool structure, tool material, tool wear, and so on [10,11]. Ren et al. [12] proposed a hybrid model coupled thermo-mechanical effects for predicting residual stress and microstructure modification in turning of Inconel 718, they found that both the microhardness and grain size decreased at larger cutting forces. Arrazola et al. [13] found that due to the additional thermomechanical stresses, more surface defects were found in machining with worn tools, especially when flank wear width exceeded $0.15 \mathrm{~mm}$. Based on the chip formation, tool wear and tool edge radius, a mechanistic force model was proposed by Orra et al. [14], the simulated results showed that increase in 
flank wear width led to dramatic increase in the cutting force. Same observation was also reported by Kamdani et al. [15] when milling of Inconel 718.

Except for the cutting force and temperature, tool wear also has a significant effect on the surface topography. M'Saoubi et al. [16] reported that during turning of Inconel 718, a wavier and worse surface was generated from a worn coated carbide tool. Zhang et al. [17] established a simulation model that considered tool flank wear for the prediction of surface topography during the ball-end milling process. The experimental results concerning the milled surface topography are consistent with the model predictions. Jafarian et al. [18] found that an increase in the machining time could result in a high $R_{\mathrm{a}}$ value when turning Inconel 718, and the effect of tool wear on $R_{\mathrm{a}}$ could be negligible within $120 \mathrm{~s}$ turning time. Conversely, it has been reported that a lower $R_{\mathrm{a}}$ value is achieved with slightly worn tools, this is because the wear scars on the tool flank surface reduces the peak heights of the machined surface profiles which acts as a wiper $[19,20]$. In other words, slight tool wear would make the tool-workpiece contact surface more adaptable. Unfortunately, a dramatic increase of the $R_{\mathrm{a}}$ value would inevitably occur at the end of the tool lifetime due to the large tool wear and its fractured cutting edges.

During machining process, the induced residual stress and work hardening are associated with the coupled thermo-mechanical effects [1]. High thermal gradients tend to generate tensile stress and softening phenomena at small depths below the surface, whereas the extrusion effect produced by mechanical loads contribute to induce compressive residual stress and work hardening [21-24]. The final residual stress and microhardness depend on the thermal or mechanical effects which one playing the dominant role $[25,26]$. Normally, tool wear increases the enhanced thermal effects more than the mechanical effect, thus tensile residual stresses are induced especially at the surface. Aspinwall et al. [27] and Soo et al. [28] found that when milling with new and worn tools, the surface tensile residual stress of Inconel 718 increased with tool wear due to the dominant thermal effects. Peng et al. [29] reported experimental investigations on the induced residual stress distributions with new, semi-worn, and worn tools. The results showed that for worn tools, the tensile residual stresses were distributed within approximately $50 \mu \mathrm{m}$ beneath the machined surface, while the residual stresses distributed within the range of 50-300 $\mu \mathrm{m}$ were compressive. Niaki and Mears obtained similar conclusions when turning of Inconel 718 [30], large tensile residual stresses were generated at $0.05 \mathrm{~mm}$ distance from the surface and then small compressive residual stress occurred.

The effects of tool wear on the microhardness of nickel-based superalloys have been discussed in several works. General trends indicate that the microhardness increases with tool wear due to severe plastic deformation, nose extrusion, and friction between tool-workpiece interface [31, 32]. Zhuang et al. [33] obtained the in-depth microhardness distributions under different flank wears when dry turning of Inconel 718, a work-hardened layer of $0.23 \mathrm{~mm}$ thickness was found under the notch wear width and depth of $0.2 \mathrm{~mm}$ and $0.12 \mathrm{~mm}$, respectively. Hood et al. [34] found that when turning RR1000 superalloy, compared with the new tool, the worn tools could produce a deeper work-hardened layer and a higher microhardness value of $50 \mathrm{HK}$. The microstructure alteration induced by tool wear has been analyzed using different micro-examination techniques. M'Saoubi et al. [16] found that the misorientation value 
was larger when turning Inconel 718 using worn tools compared with new tools. Zhou et al. [35] found that when turning Inconel 718 with new and worn tools, the thickness of subsurface plastic deformation layer increased with the tool flank wear, which could be explained by the increased thermo-mechanical loads. Similar results were found by Agmell et al. [36], the relative strain was large when using worn tools.

Most published works have focused on the surface integrity of Inconel 718 during turning process, but few considered the high-speed end milling process. This study evaluates the effects of tool wear on the surface integrity during milling of Inconel 718 . The machined surface integrity characteristics under various flank wear conditions were examined based on the surface roughness and topography in the surface, residual stress, microhardness, and microstructure in the subsurface. Moreover, the cutting force and temperature were analyzed to further explain the mechanisms of surface integrity characteristics.

\section{Experimental Work \\ 2.1. Material}

The workpiece material used in this investigation was a nickel-based superalloy Inconel 718. Its chemical composition is $16.5-21.0 \% \mathrm{Cr}, 11.5-22.5 \% \mathrm{Fe}, 4.5-5.85 \% \mathrm{Nb}, 0.75-1.20 \% \mathrm{Ti}, 2.5-3.5 \% \mathrm{Mo}, 0.4-0.6 \% \mathrm{Al}$, $<0.70 \% \mathrm{Si},<0.5 \% \mathrm{Mn},<0.1 \% \mathrm{C},<0.04 \% \mathrm{~S}, 0.005 \% \mathrm{~B}$, and Ni balance (in wt \%). The heat treatment procedure of the Inconel 718 is: at $720^{\circ} \mathrm{C}$ for 8 hours, furnace cooled to $620^{\circ} \mathrm{C}$ and holding for 8 hours, air cool [37]. The yield and tensile strengths of the as received material were 1336 and $1485 \mathrm{MPa}$ at normal temperature, respectively. Figure 1 presents the matrix microstructure of Inconel 718, which consists of spot-like $\delta$ phase $\left(\mathrm{Ni}_{3} \mathrm{Nb}\right)$ and some $\mathrm{NbC}$ carbides. The $\delta$ phases are scattered in the grains irregularly. The used workpiece material was cut into wedge block using wire electrical discharge machine. The dimensions and workpiece inclination angle are $50 \mathrm{~mm} \times 50 \mathrm{~mm} \times 50 \mathrm{~mm}\left(L_{0} \times W_{0} \times H_{0}\right)$ and $60^{\circ}$, as shown in Fig. 2.

\subsection{Experimental procedures}

All milling tests were performed on a VMC-850 machine with spindle power of $25 \mathrm{~kW}$, rotational speeds of $8,000 \mathrm{rpm}$, and linear feed rates of $5 \mathrm{~m} / \mathrm{min}$. Coated carbide ball nose end milling tools were used in this work, which has four flutes of $8 \mathrm{~mm}$ in diameter and $60 \mathrm{~mm}$ in length. In order to prepare cutting tools with different flank wear, the layer-to-layer cutting method with horizontal upward cutter path orientation was used to cut the Inconel 718 workpiece. The tool overhang length was kept as $30 \mathrm{~mm}$, the employed milling parameters were set as cutting speed $v_{\mathrm{c}}=40 \mathrm{~m} / \mathrm{min}$, feed rate per flute $f_{\mathrm{z}}=0.02 \mathrm{~mm} / \mathrm{z}$, cutting axial depth $a_{\mathrm{p}}=0.4 \mathrm{~mm}$, and cutting radial depth $a_{\mathrm{e}}=0.25 \mathrm{~mm}$. After cutting for 20 minutes, the cutting tool was removed from the machine spindle to measure the tool flank wear. Three flank wear widths of $0.1,0.2$, and $0.3 \mathrm{~mm}$ were obtained under these cutting conditions. Then, the worn tools were used to cut a new material specimen. Down milling under dry cutting was performed for all milling processes.

Cutting forces were measured during tool wear propagation using a force measuring system, which consists of a piezoelectric dynamometer (9255B, Kistler, Switzerland), a charge amplifier (5080A, Kistler, 
Switzerland), a data acquisition card (Sirius, DEWESoft, Austria), and a computer with the DEWESoft software. To obtain the generated cutting temperature distribution when using worn tools, a commercial software AdvantEdge was applied to simulate the orthogonal cutting process. A two-dimensional finite element-based machining model was established, and the arbitrary Lagrangian-Eulerian approach and the Johnson-Cook constitutive equation were applied for the numerical modeling. The element topology was a six-node quadratic triangle element with three corners and three midsize nodes. Continuous adaptive remeshing was used to correct for element distortion due to large deformations. The minimum and maximum lengths of these elements in the tool-workpiece interface was set to 0.005 and $0.01 \mathrm{~mm}$, respectively. Carbide-General was used as he cutting tool material, which was assumed to be rigid. The tool rake angle, clearance angle, cutting edge radius, and flank wear width were set as the actual value. The Coulomb's friction law was used with a work tool friction coefficient value of 0.4. The cutting parameters used in the simulation were calculated according to the workpiece inclination angle and the actual parameters used in the experiments.

\subsection{Tool wear and surface integrity measurements}

The tool flank wear and its morphology were measured using a tool microscope (IF-EdgeMaster, Alicona, Austria). Four cutting flutes were measured, and the average flank wear width was calculated. A contacttype surface profiler (MarSurf XR 20, Mahr, Germany) was used to measure the surface roughness. The cutoff length, evaluation length and measuring speed were $0.8 \mathrm{~mm}, 4 \mathrm{~mm}$, and $0.5 \mathrm{~mm} / \mathrm{s}$, respectively. Five points were taken along pick feed direction and the average value was obtained. The 3D surface topography was observed at a measuring interval of $0.5 \mu \mathrm{m}$ over a measuring region of $1 \mathrm{~mm} \times 1 \mathrm{~mm}$.

An X-ray stress analyzer (LXRD MG2000, Proto, Canada) with $\sin ^{2} \psi$ method was used to determine the residual stresses. The detailed measurement conditions were as follows: $\mathrm{Mn} \mathrm{K}_{\mathrm{a}}$ radiation, diffraction angle $151.88^{\circ}$, diffraction planes (311), X-ray beam diameter $1 \mathrm{~mm}$, tube voltage $20 \mathrm{kV}$, tube current 20 $\mathrm{mA}$, exposure time $1 \mathrm{~s}$, and exposure number 10 . The electrolytic polishing technique was used to remove the surface material with a saturated solution of $\mathrm{CH}_{3} \mathrm{OH} / \mathrm{C}_{6} \mathrm{H}_{14} \mathrm{O}_{2} / \mathrm{HClO}_{4}$ (10:5:1 by volume). Layer removal in steps of approximately $20 \mu \mathrm{m}$ and residual stress measurement were applied alternatively, then the in-depth residual stress distribution can be obtained.

Several steps of cleaving, inlaying, sanding, polishing, and etching were used to prepare the crosssections of the specimens. Microhardness Measurements along the depth direction were taken using a micro-Vickers hardness tester (FM-800, Future-Tech, Japan) with $25 \mathrm{gf}$ load and 10 s holding time. To reduce measurement errors, the distance between the two test points was more than twice that of the indentation diagonal line. The cross-sectional microstructure image was observed by a scanning electron microscope (TM4000puls, Hitachi, Japan). To ensure the microstructure was more discernible for microscopic observation, a chemical solution of $\mathrm{HF} / \mathrm{HCl} / \mathrm{H}_{2} \mathrm{O}_{2}(5: 2: 1$ by volume) was used to etch the test surfaces for approximately $30 \mathrm{~s}$.

\section{Results And Discussion}




\subsection{Tool wear and tool lifetime}

The measured function curve of flank wear propagation with cutting time is shown in Fig. 3. The tool flank wear width has three typical stages of initial running into wear, middle steady wear, and final sharp wear. The wear rate of the initial wear stage from $0-70 \mathrm{~min}$ is very high due to the small tool edge radius. The interim steady wear stage from 70-310 min lasts the majority of the tool lifetime with a low wear rate. The final sharp wear stage from 310-380 min lasts for the shortest cutting time and has the highest wear rate. Similar phenomena were observed when whole end milling of Inconel 718 [38], high-speed turning of RR1000 [34], and ball nose end milling of TC17 [10]. When the cutting time is above 320 min, both the flank wear width (reaches $0.25 \mathrm{~mm}$ ) and rate are significantly enhanced. When the cutting time is above $350 \mathrm{~min}$, the flank wear width reaches the service limit value $(0.3 \mathrm{~mm})$ for the ball nose end mill in practical engineering.

The tool wear morphology from the initial cut to VB $0.3 \mathrm{~mm}$ is presented in Fig. 4. The cutting edges under different cutting stages have similar flank wear features. In Fig. 4(b), a bright strip is formed during tool flank wear propagation due to the exfoliation of the tool material. Wear pit can be seen in Fig. 4 (c), this is because the wear debris of the tool material is stuck on and taken away by the cutting chips. In Fig. 4(d), the flank wear area is a rectangle with a rough and nonuniform surface with some small pits, which proves the cutting process is unstable. The tool side cutting edge angle is strongly influenced by the flank wear, which could diminish the cutting aggressiveness of the tool [39].

\subsection{Cutting force and temperature}

The effects of tool flank wear on the resultant cutting force and highest cutting temperature are shown in Fig. 5. With the increase of tool flank wear width, the cutting force increases linearly. As the tool flank wear width reaches $0.3 \mathrm{~mm}$, the cutting force is over $200 \mathrm{~N}$, which is twice the initial value. Moreover, the simulated highest cutting temperature increases at higher flank wears until VB $=0.2 \mathrm{~mm}$, where the highest temperature of approximately $560^{\circ} \mathrm{C}$ is achieved. Further growth in the flank wear causes the cutting temperature to then decrease. The high cutting temperature generated with the worn tools can induce tensile residual stress, phase transformation, and microchip debris adhesion to the machined surface [40]. Fan et al. [41] indicated that there was an optimal temperature of $650^{\circ} \mathrm{C}$ that makes the tool workpiece have its highest strength ratio and reduces the material adhesion when machining Inconel 718. Compared with the simulated value, the measured cutting force is slightly smaller, this is because the lubricative effect of the cutting fluid. Errors in the simulated cutting force are mostly in the range of 7$19 \%$, which verifies the accuracy of the finite element method analysis.

The cutting temperature distribution under various flank wear conditions is shown in Fig. 6. A hightemperature area is developed at the workpiece-tool-chip contact interface. The highest cutting temperature is mostly in the range of $483-559^{\circ} \mathrm{C}$, which appears at the tip of the cutting tool. According to Fan et al. [41], the cutting temperature corresponding to different normal loads with various cutting speeds for Inconel 718 is around $520-727^{\circ} \mathrm{C}$. This indicates that this finite element model can accurately predict the temperature distributions near the workpiece-tool-chip contact interface. The temperature of 
the serrated chip is significantly higher compared with that of the workpiece and tool. This is because the cutting chips remove the majority of the heat, a fraction of the heat dissipates in the air, and the residual heat transmits into the subsurface [18]. Moreover, it is seen that the length of the cutting chips as induced by worn tools is smaller than that induced by new tools, where the thickness of the cutting chips also decreases. This is attributed to the enhanced cutting-edge radius and flattened flank face, which results in a decreased axial depth of cut. This is also why the highest cutting temperature decreases to $496^{\circ} \mathrm{C}$ when the tool flank wear width is $0.3 \mathrm{~mm}$.

The temperature data of the machined subsurface layer is extracted and the in-depth temperature distributions for various tool flank wear widths are plotted in Fig. 7. A gradual heat-affected layer forms readily and the cutting temperature decreases gradually with the increased depth beneath surface. The heat-affected layer depth induced by new tools is approximately $60 \mu \mathrm{m}$, which is slightly shallower compared with that induced by worn tools $(80 \mu \mathrm{m})$. This is because more cutting heat is generated by worn tools and transfers deeper below the machined surface.

\subsection{Surface integrity}

\subsubsection{Surface roughness and topography}

The $R_{\mathrm{a}}$ and $S_{\mathrm{a}}$ value of the specimens machined using new and worn tools are shown in Fig. 8. We can see that during the initial cutting stage, a relatively large surface roughness appears due to the sharp tool tip. The surface roughness decreases slightly at larger VB value until a specific width of $0.1 \mathrm{~mm}$ where the lowest $R_{\mathrm{a}}$ and $S_{\mathrm{a}}$ values are obtained. This is because the peaks of the tool marks are removed due to the enhanced flank wear face and raised radius of the blunt tool tip, which results in a decreased surface roughness. As the VB value further increases, the cutting edge becomes irregular that result in obvious scratches on the surface. When VB value reaches $0.2 \mathrm{~mm}$, the $R_{\mathrm{a}}$ value is more than $1.0 \mu \mathrm{m}$, which can no longer satisfy the design requirements. Thus, worn tools cannot be used, even though tool flank wear width does not reach the tool wear criterion. As VB value is $0.3 \mathrm{~mm}$, the $R_{\mathrm{a}}$ and $S_{\mathrm{a}}$ values are more than $2.5 \mu \mathrm{m}$ and $1.8 \mu \mathrm{m}$ due to a loss in the tool cutting performance.

The surface topographies of specimens machined with new and worn tools are shown in Fig. 9. As shown in Figs. 9(a) and (b), the surface is relatively smooth and accompanied with limited sharp peaks and grooves. There is no obvious distinction between the machined topographies induced by new tools and slightly worn tools $(\mathrm{VB}=0.1)$. The results indicate that during the initial wear stage, the tool flank wear has a relatively low influence on the surface topography. As the tool flank wear width further increases, large grooves and folds occur due to the effects of extrusion. The depth of grooves is enhanced and the ridges become more irregular at VB value of $0.3 \mathrm{~mm}$. The observed surface topographies are consistent with the measured surface roughness. It is noted that the tool flank wear width below $0.2 \mathrm{~mm}$ can guarantee the surface roughness and topography during ball nose end milling of Inconel 718,

\subsubsection{In-depth residual stress distribution}


Figure 9 presents the in-depth residual stress distributions when milling Inconel 718. The same spoonshaped profiles of the residual stress are obtained under new and worn tools, which are maximized in compression at a 20-30 $\mu \mathrm{m}$ depth beneath the surface, then gradually decrease, and finally reach a steady value. Tensile residual stress of 100-250 MPa is detected on the surface at VB value of 0.2 and $0.3 \mathrm{~mm}$, while compressive residual stress of $-100--450 \mathrm{MPa}$ is detected on the surface at VB value of 0 and $0.1 \mathrm{~mm}$. The surface tensile residual stress can be explained by the high cutting temperature gradients as caused from severe rubbing and plowing between the tool-workpiece interface [42]. This indicates that the enhanced thermal effect is dominant under larger tool flank wear width that results in tensile stress [29], especially along the feed direction at VB value of $0.3 \mathrm{~mm}$. However, the residual stress in subsurface is comprehensive, and the affected layers of the compressive residual stress are $80-120$ $\mu \mathrm{m}$ in thickness, regardless of the tool wear and measured directions. The maximum compressive residual stress increases as the tool flank wear width increases. A possible reason is that the increased cutting temperature only has a limited effect on the compressive residual stress affected layer. Aspinwall et al. [27] found that the surface residual stress depended on the workpiece angle and cutter orientation, while the thickness of the residual stress affected layer became much deeper for larger tool wear width.

As shown in Fig. 10(b), the maximum surface compressive residual stress of $-454 \mathrm{MPa}$ is achieved with the lowest affected layer depth of $80 \mu \mathrm{m}$ under a VB value of $0.1 \mathrm{~mm}$. When the VB value reaches 0.2 $\mathrm{mm}$, the thickness of affected layer is $120 \mu \mathrm{m}$ and the maximum compressive residual stress is -647 $\mathrm{MPa}$ which locates at $20 \mu \mathrm{m}$ beneath the machined surface. As seen from Fig. 9(a), the maximum magnitude of compressive residual stresses is within the range of -500 to $-700 \mathrm{MPa}$, which is larger than that measured along the feed direction ( -300 to $-500 \mathrm{MPa}$ ) shown in Fig. 9(b). A similar phenomenon was observed when investigated the residual stress distributions of TC17 alloy as induced by ultrasonic surface rolling [43]. A possible reason for this phenomenon is that the pick feed force component increases more prominently compared with the feed force component.

\subsubsection{In-depth microhardness distribution}

Figure 11 presents the in-depth microhardness distributions under different VB values. Gradual workhardened layers are observed under VB values of 0 and $0.1 \mathrm{~mm}$, and the surface microhardness value along pick feed direction reaches up to $618 \mathrm{HV}_{0.025}$, which is approximately $28 \%$ greater than the microhardness in bulk material. Then the microhardness decreases rapidly within the range of $0-40 \mu \mathrm{m}$, finally fluctuates from 450 to $500 \mathrm{HV}_{0.025}$. However, the microhardness induced under VB value of 0.2 $\mathrm{mm}$ and $0.3 \mathrm{~mm}$ changes little. Comparing the microhardness shown in Fig. 11 indicates that the indepth microhardness value along the pick feed direction is slightly higher than that along the pick feed direction. This shows that there is a consistency between the residual stress and microhardness. A possible explanation could be due to different plastic deformations, dislocation densities, and grain refinements along the two directions.

As seen in Fig. 11 (b), the surface microhardness produced with new tools (maximum value is 618 $\left.\mathrm{HV}_{0.025}\right)$ is larger than that from worn tools. The drop in microhardness levels induced by worn tools is 
mainly due to the strain relief as caused from the high expected cutting temperatures. However, work hardening is more often observed in worn tools compared with new tools. Milling with worn tools causes an increased tool-workpiece contact area due to reductions in the of flank angle, which leads to an escalation of the thermo-mechanical loads and plastic deformation. High cutting temperatures in the cutting area induce a softening layer in the microhardness, whereas work hardening is generally indicative of high machining pressures and cutting forces during chip formation. The small thermal conductivity of Inconel $718\left(18.3 \mathrm{~W} / \mathrm{m}^{\circ}{ }^{\circ} \mathrm{C}, 400^{\circ} \mathrm{C}\right)$ causes a cutting heat to accumulate on the surface area, which results in a low microhardness [37]. Similar results were described by Soo et al. [44], Ezugwu et al. [45], and Sharman et al. [19] when turning Inconel 718.

\subsubsection{Microstructure observation}

Images of the microstructure machined using new and worn tools are shown in Fig. 12. During milling, microstructure alternation occurs due to interactions between the strain hardening and thermal softening. An uneven milled surface, broken lattice, and deformed grains are observed at a magnification of 2000x. A gradient microstructure is produced at the subsurface layer, and the plastic deformation decreases as the depth increases. The thickness of the plastic deformed layer varies within tens of micrometers, and increasing the tool flank wear exaggerates the plastic deformation depth, which can be explained by the severe rubbing. Agmell et al. [36] also found a gradient microstructure when turning Inconel 718.

A surface cavity is observed on the milled surface in Fig. 12(a), which is associated with the NbC particles. In general, carbide particles are hard and brittle, and can decrease the tool lifetime while inducing defects on machined surfaces. Flaky exfoliation of the workpiece surface material is also observed. Small surface material particles are plucked and removed by the cutting chips. More flaking material is observed under larger flank wear conditions. Material strain streamlines are observed in Figs. 12 (a) - (d). This is likely due to the grains being elongated and rotated along the tool feed direction

during milling. Moreover, the slope of the streamline increases with the flank wear. In Fig. 12 (d), the angle between the material strain streamlines and the feed direction is very small, and the streamlines have good consistency, which indicates that severe plastic flow occurs under the VB value of $0.3 \mathrm{~mm}$.

\section{Conclusions}

The cutting force, temperature, tool flank wear, and surface integrity characteristics were investigated during ball-end milling Inconel 718. The effects of tool flank wear on the surface integrity characteristics were analyzed. The conclusions of this paper are summarized as follows:

(1) For a VB value of $0.3 \mathrm{~mm}$, the tool lifetime is approximately $350 \mathrm{~min}$. The cutting force increases with the increase of VB value, while the simulated cutting temperature has a downward trend at a VB value of $0.3 \mathrm{~mm}$. The simulated highest cutting temperature is $480-560^{\circ} \mathrm{C}$ and the thickness of the heat-affected layer is approximately $80 \mu \mathrm{m}$. 
(2) A higher tool flank wear width produces a larger surface roughness, and more than $R_{\mathrm{a}} 2.5 \mu \mathrm{m}$ is achieved when the VB value reaches $0.3 \mathrm{~mm}$. Wavier surface sharp peaks and grooves are generated, and a distinct surface topography deterioration is observed for larger tool flank wear widths.

(3) The in-depth residual stress distribution is directly affected by the tool flank wear. An increased tool flank wear causes a high-amplitude and deep layer of compressive residual stress (approximately - 700 MPa and $120 \mu \mathrm{m}$ ). Work-hardened layer of $60 \mu \mathrm{m}$ and enhanced surface microhardness are induced. The surface microhardness induced by new tools is $618 \mathrm{HV}_{0.025}$, which is larger than that induced by worn tools (in the range of $460-530 \mathrm{HV}_{0.025}$ ).

(4) Uneven milled surfaces, broken lattices, and deformed grains are observed in the subsurface microstructure. The strain streamline with a slope towards deeper layers is observed within $10 \mu \mathrm{m}$ below the surface. The strain streamlines have good consistency and are nearly parallel to the tool feed direction at a VB value of $0.3 \mathrm{~mm}$.

\section{Declarations}

\section{Acknowledgements}

The authors deeply acknowledge the Key Laboratory of High Performance Manufacturing for Aero Engine (Northwestern Polytechnical University) and Engineering Research Center of Advanced Manufacturing Technology for Aero Engine (Northwestern Polytechnical University), for providing us with the ability to conduct this research.

\section{Authors Contributions}

Conceptualization, Changfeng Yao and Dinghua Zhang; methodology, Liang Tan; investigation and data analysis, Liang Tan and Xuehong Shen; writing-original draft preparation, Liang Tan; writing-review \& editing, Liang Tan and Minchao Cui; funding acquisition, Liang Tan, Changfeng Yao, and Dinghua Zhang.

\section{Funding}

This work was supported by the National Natural Science Foundation of China [Nos. 51905440 and 51875472], the Fundamental Research Funds for the Central Universities [No. 31020200502002], the Natural Science Basic Research Plan in Shaanxi Province of China [No. 2020JQ-186], the National Natural Science Foundation of China [No. 91860206], and the National Science and Technology Major Project of China [No. 2017-VII-0001-0095].

\section{Availability of data and materials}

Not applicable.

\section{Ethics approval}


This paper does not require any ethical approval as the study does not involve human participants or animals.

\section{Consent to Participate}

Not applicable as this work does not involve human subjects.

\section{Consent to Publish}

The work described is accomplished in our laboratory and has not been published or under consideration for publication elsewhere. All authors have read and approve this version of the article, and due care has been taken to ensure the integrity of the work.

\section{Competing Interests}

The authors declare that they have no competing interests.

\section{References}

1. Ulutan D, Ozel T (2011) Machining induced surface integrity in titanium and nickel alloys: a review. Int J Mach Tools Manuf 51(3):250-280. https://doi.org/10.1016/j.jmmachtools.2010.11.003

2. Ezugwu EO, Wang ZM, Okeke $\mathrm{Cl}$ (1999) Tool life and surface integrity when machining Inconel 718 with PVD- and CVD-coated tools. Tribol Trans 42(2):353-360. https://doi.org/10.1080/10402009908982228

3. Arunachalam R, Mannan MA (2000) Machinability of nickel-based high temperature alloys. Mach Sci Technol 4(1):127-168. https://doi.org/10.1080/10940340008945703

4. Grzesik W, Niesłony P, Habrat W, Sieniawski J, Laskowski P (2018) Investigation of tool wear in the turning of Inconel 718 superalloy in terms of process performance and productivity enhancement. Tribol Int 118:337-346. https://doi.org/10.1016/j.triboint.2017.10.005

5. Liao YS, Lin HM, Wang JH (2008) Behaviors of end milling Inconel 718 superalloy by cemented carbide tools. J Mater Process Technol 201(1-3):460-465. https://doi.org/10.1016/j.jmatprotec.2007.11.176

6. Cai XJ, Qin S, Li JL, An QL, Chen M (2014) Experimental investigation on surface integrity of end milling nickel-based alloy-Inconel 718. Mach Sci Technol 18(1):31-46. https://doi.org/10.1080/10910344.2014.863627

7. Thakur A, Gangopadhyay S (2016) State-of-the-art in surface integrity in machining of nickel-based super alloys. Int J Mach Tools Manuf 100:25-254. https://doi.org/10.1016/j.jimachtools.2015.10.001

8. Liang XL, Liu ZQ, Wang B (2019) State-of-the-art of surface integrity induced by tool wear effects in machining process of titanium and nickel alloys: a review. Meas J Int Meas Confed 132:150-181. https://doi.org/10.1016/j.measurement.2018.09.045 
9. Wang B, Liu ZQ (2018) Influences of tool structure, tool material and tool wear on machined surface integrity during turning and milling of titanium and nickel alloys: a review. Int J Adv Manuf Technol 98(5-8):1925-1975. https://doi.org/10.1007/s00170-018-2314-1

10. Tan L, Yao CF, Ren JX, Zhang DH (2017) Effect of cutter path orientations on cutting forces, tool wear, and surface integrity when ball end milling TC17. Int J Adv Manuf Technol 88(9-12):25892602. https://doi.org/10.1007/s00170-016-8948-y

11. Liang XL, Liu ZQ, Wang B, Hou X (2018) Modeling of plastic deformation induced by thermomechanical stresses considering tool flank wear in high-speed machining Ti-6Al-4V. Int J Mech Sci 140:1-12. https://doi.org/10.1016/j.ijmecsci.2018.02.031

12. Ren XP, Liu ZQ (2019) A simulation model for predicting surface integrity coupled thermalmechanical effect in turning of Inconel 718 super alloy. Int J Adv Manuf Technol 100(5-8):18251837. https://doi.org/10.1007/s00170-018-2704-4

13. Arrazola PJ, Garay A, Fernandez E, Ostolaza K (2014) Correlation between tool flank wear, force signals and surface integrity when turning bars of Inconel 718 in finishing conditions. Int $\mathrm{J}$ Mach Mach Mater 15(1-2):84-100. https://doi.org/10.1504/IJMMM.2014.059193

14. Orra K, Choudhury SK (2018) Mechanistic modelling for predicting cutting forces in machining considering effect of tool nose radius on chip formation and tool wear land. Int J Mech Sci 142143:255-268. https://doi.org/10.1016/j.ijmecsci.2018.05.004

15. Kamdani K, Ashaary I, Hassan S, Lajis MA (2019) The effect of cutting force and tool wear in milling Inconel 718. J Phys Conf Ser 1150:012046. https://doi.org/10.1088/1742-6596/1150/1/012046

16. M'Saoubi R, Larsson T, Outeiro J, Guo Y, Suslov S, Saldana C, Chandrasekar S (2012) Surface integrity analysis of machined Inconel 718 over multiple length scales. CIRP Ann - Manuf Technol 61(1):99-102. https://doi.org/10.1016/j.cirp.2012.03.058

17. Zhang C, Guo S, Zhang HY, Zhou LS (2013) Modeling and predicting for surface topography considering tool wear in milling process. Int J Adv Manuf Technol 68(9-12):2849-2860. https://doi.org/10.1007/s00170-013-4989-7

18. Jafarian F, Umbrello D, Golpayegani S, Darake Z (2016) Experimental investigation to optimize tool life and surface roughness in Inconel 718 machining. Mater Manuf Process 31(13):1683-1691. https://doi.org/10.1080/10426914.2015.1090592

19. Sharman ARC, Hughes Jl, Ridgway K (2004) Workpiece surface integrity and tool life issues when turning Inconel 718 ${ }^{\mathrm{TM}}$ nickel based superalloy. Mach Sci Technol 8(3):399-414. https://doi.org/10.1081/MST-200039865

20. Fernández-Valdivielso A, López De Lacalle LN, Urbikain G, Rodriguez A (2016) Detecting the key geometrical features and grades of carbide inserts for the turning of nickel-based alloys concerning surface integrity. Proc Inst Mech Eng Part C J Mech Eng Sci 230(20):3725-3742. https://doi.org/10.1177/0954406215616145

21. Thakur DG, Ramamoorthy B, Vijayaraghavan L (2012) Effect of cutting parameters on the degree of work hardening and tool life during high-speed machining of Inconel 718. Int J Adv Manuf Technol 
59(5-8):483-489. https://doi.org/10.1007/s00170-011-3529-6

22. Zhou JM, Bushlya V, Peng RL, Chen Z, Johansson S, Stahl JE (2014) Analysis of subsurface microstructure and residual stresses in machined Inconel 718 with PCBN and Al203-SiCw tools. Procedia CIRP 13:150-155. https://doi.org/10.1016/j.procir.2014.04.026

23. Chen Z, Peng RL, Avdovic P, Moverare J, Karlsson F, Zhou JM, Johansson S (2014) Analysis of thermal effect on residual stresses of broached Inconel 718. Adv Mater Res 996:574-579. https://doi.org/10.4028/www.scientific.net/AMR.996.574

24. Shan CW, Zhang MH, Zhang SN, Dang J (2020) Prediction of machining-induced residual stress in orthogonal cutting of Ti6Al4V. Int J Adv Manuf Technol 107:2375-2385. https://doi.org/10.1007/s00170-020-05181-5

25. Yan L, Yang WY, Jin HP, Wang ZG (2012) Analytical modeling of the effect of the tool flank wear width on the residual stress distribution. Mach Sci Technol $16: 265-286$. https://doi.org/1080/10910344.2012.673973

26. Choi $Y(2010)$ Influence of tool flank wear on performance of finish hard machined surfaces in rolling contact. Int J Fatigue 32(2):390-397. https://doi.org/10.1016/j.ijfatigue.2009.07.014

27. Aspinwall DK, Dewes RC, Ng EG, Sage C, Soo SL (2007) The influence of cutter orientation and workpiece angle on machinability when high-speed milling Inconel 718 under finishing conditions. Int J Mach Tools Manuf 47(12-13):1839-1846. https://doi.org/10.1016/j.ijmachtools.2007.04.007

28. Soo SL, Hood R, Aspinwall DK, Voice WE, Sage C (2011) Machinability and surface integrity of RR1000 nickel based superalloy. CIRP Ann - Manuf Technol 60(1):89-92. https://doi.org/10.1016/j.cirp.2011.03.094

29. Peng RL, Zhou JM, Johansson S, Bellinius A, Bushlya V, Ståhl JE (2014) Influence of dry cut and tool wear on residual stresses in high speed machining of nickel-based superalloy. Mater Sci Forum 768769:470-477. https://doi.org/10.4028/www.scientific.net/MSF.768-769.470

30. Niaki FA, Mears L (2017) A comprehensive study on the effects of tool wear on surface roughness, dimensional integrity and residual stress in turning IN718 hard-to-machine alloy. J Manuf Process 30:268-280. https://doi.org/10.1016/j.jmapro.2017.09.016

31. Sharman ARC, Hughes JI, Ridgway K (2015) The effect of tool nose radius on surface integrity and residual stresses when turning Inconel 718 ${ }^{\mathrm{TM}}$. J Mater Process Technol 216:123-132. https://doi.org/10.1016/j.jmatprotec.2014.09.002

32. Li W, Guo YB, Barkey ME, Jordon JB (2014) Effect tool wear during end milling on the surface integrity and fatigue life of Inconel 718. Procedia CIRP 14:546-551. https://doi.org/10.1016/j.procir.2014.03.056

33. Zhuang KJ, Zhu DH, Zhang XM, Ding H (2014) Notch wear prediction model in turning of Inconel 718 with ceramic tools considering the influence of work hardened layer. Wear 313(1-2):63-74. https://doi.org/10.1016/j.wear.2014.02.007

34. Hood R, Soo SL, Aspinwall DK, Mantle AL (2018) Tool life and workpiece surface integrity when turning an RR1000 nickel-based superalloy. Int J Adv Manuf Technol 98(9-12):2461-2468. 
https://doi.org/10.1007/s00170-018-2371-5

35. Zhou JM, Bushlya V, Peng RL, Johansson S, Avdovic P, Stahl J (2011) Effects of tool wear on subsurface deformation of nickel-based superalloy. Procedia Eng 19:407-413. https://doi.org/10.1016/j.proeng.2011.11.133

36. Agmell M, Ahadi A, Zhou JM, Peng RL, Bushlya V, Ståhl JE (2017) Modeling subsurface deformation induced by machining of Inconel 718. Mach Sci Technol 21(1):103-120. https://doi.org/10.1080/10910344.2016.1260432

37. Wu DX, Yao CF, Zhang DH (2018) Surface characterization and fatigue evaluation in GH4169 superalloy: Comparing results after finish turning; shot peening and surface polishing treatments. Int J Fatigue 113:222-235. https://doi.org/10.1016/j.ijfatigue.2018.04.009

38. Li Q, Gong YD, Cai M, Liu MJ (2017) Research on surface integrity in milling Inconel718 superalloy. Int J Adv Manuf Technol 92(1-4):1449-1463. https://doi.org/10.1007/s00170-017-0080-0

39. Cantero JL, Díaz-Álvarez J, Miguélez MH, Marín NC (2013) Analysis of tool wear patterns in finishing turning of Inconel 718. Wear 297: 885-894. https://doi.org/10.1016/j.wear.2012.11.004

40. Yang HC, Chen ZT, Zhou ZT (2015) Influence of cutting speed and tool wear on the surface integrity of the titanium alloy Ti-1023 during milling. Int J Adv Manuf Technol 78(5-8):1113-1126. https://doi.org/10.1007/s00170-014-6593-x

41. Fan YH, Hao ZP, Zheng ML, Sun FL, Yang SC (2013) Study of surface quality in machining nickelbased alloy Inconel 718. Int J Adv Manuf Technol 69(9-12):2659-2667. https://doi.org/10.1007/s00170-013-5225-1

42. Peng RL, Zhou J, Johansson S, Billenius A, Bushlya V, Stahl JE (2013) Surface integrity and the influence of tool wear in high speed machining of Inconel 718. Proceedings of the 13th International Conference on Fracture; June 16-21; Beijing, China

43. Tan L, Zhang DH, Yao CF, Ren JX (2019) Effects of ultrasonic surface rolling parameters on surface integrity of TC17 alloy. J Mater Eng Perform 28(11):6736-6745. https://doi.org/10.1007/s11665019-04418-z

44. Soo SL, Khan SA, Aspinwall DK, Harden P, Mantle AL, Kappmeyer G, Pearson D, M'Saoubi R (2016) High speed turning of Inconel 718 using PVD-coated PCBN tools. CIRP Ann - Manuf Technol 65(1):89-92. https://doi.org/10.1016/j.cirp.2016.04.044

45. Ezugwu EO, Wang ZM, Okeke $\mathrm{Cl}$ (1999) Tool life and surface integrity when machining Inconel 718 with PVD- and CVD-coated tools. Tribol Trans 42(2):353-360. https://doi.org/10.1080/10402009908982228

\section{Figures}




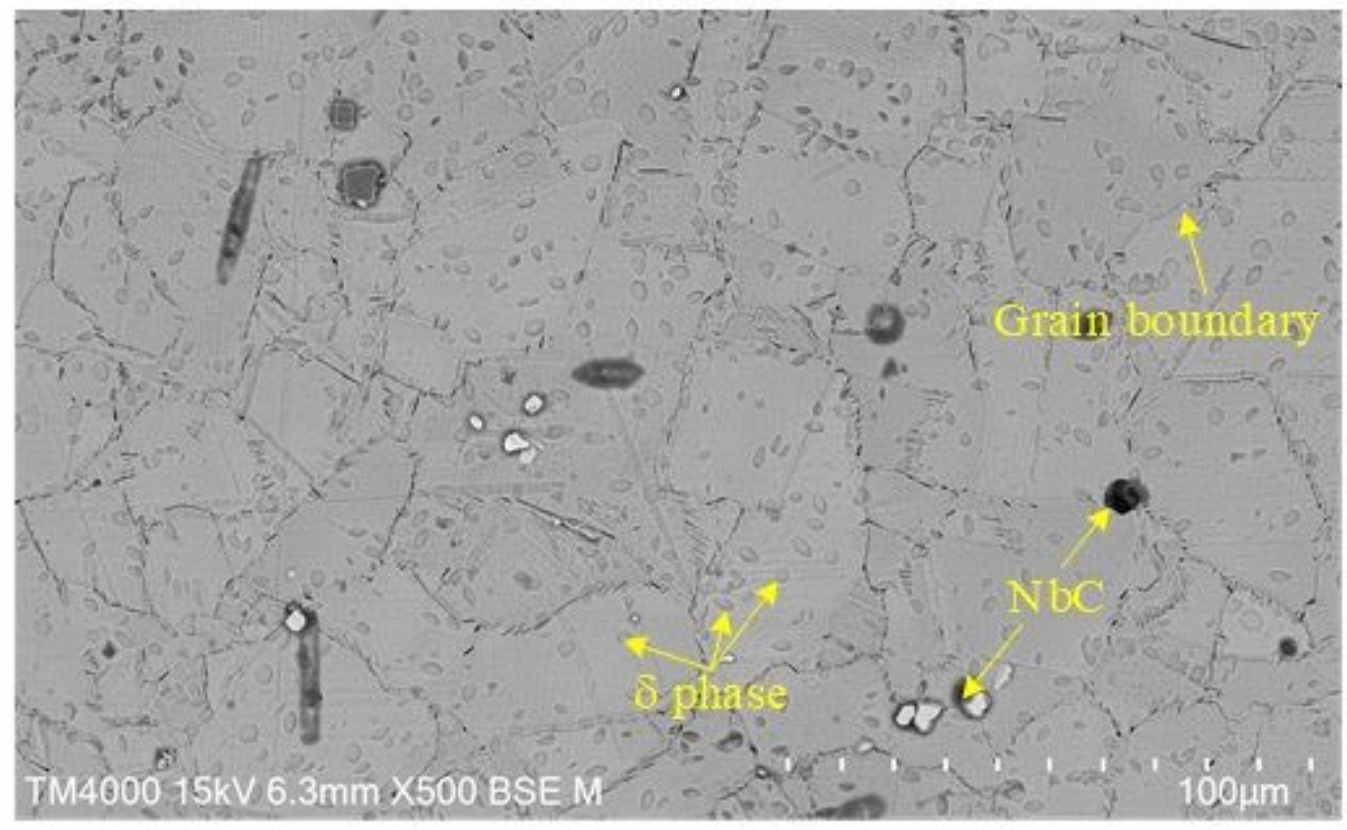

Figure 1

Original microstructure of the Inconel 718.

- Starting point Spindle rotation direction

$\longrightarrow$ Feed direction $-\rightarrow$ Pick feed direction

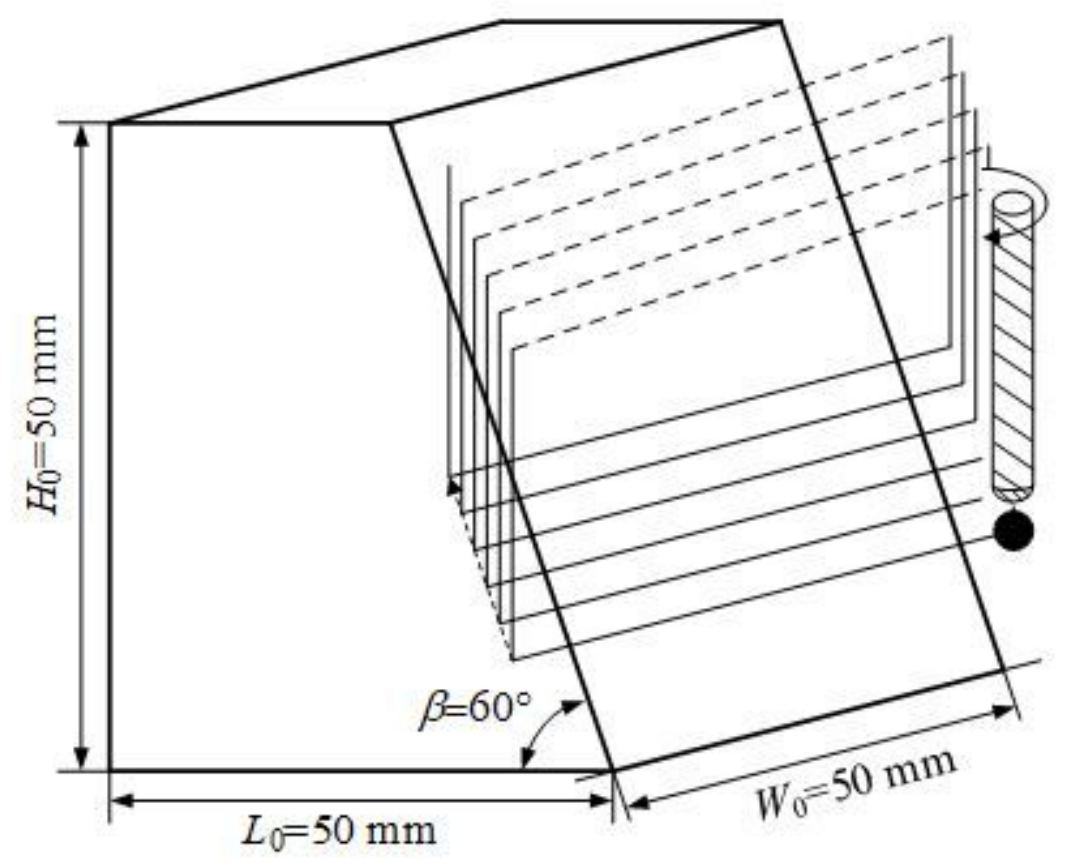

Figure 2

Dimensions of the workpiece and cutter path orientations. 


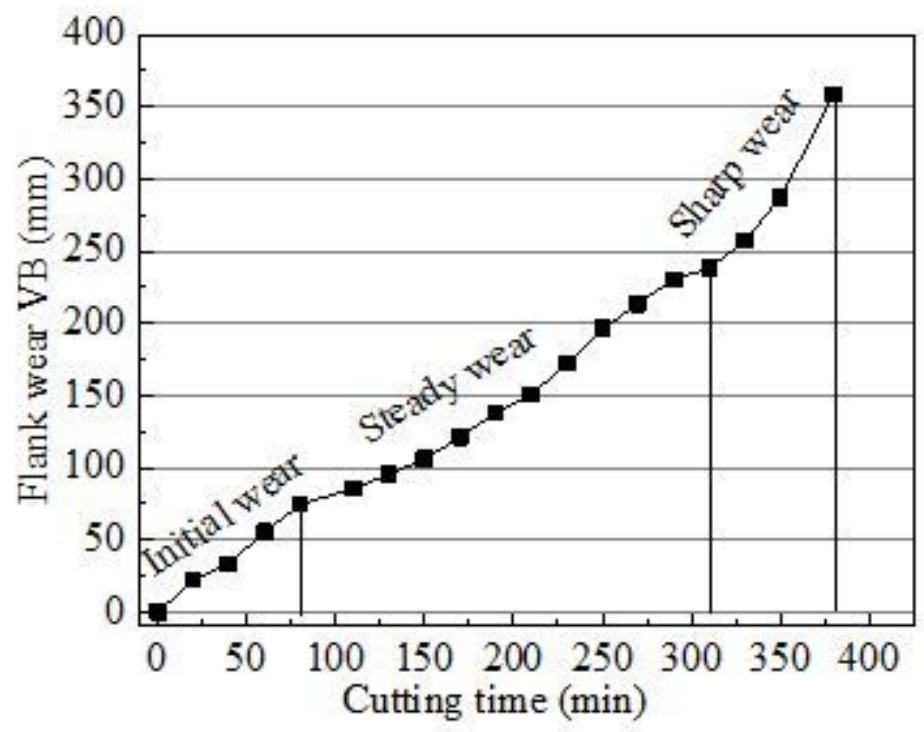

Figure 3

Flank wear propagation with cutting time.
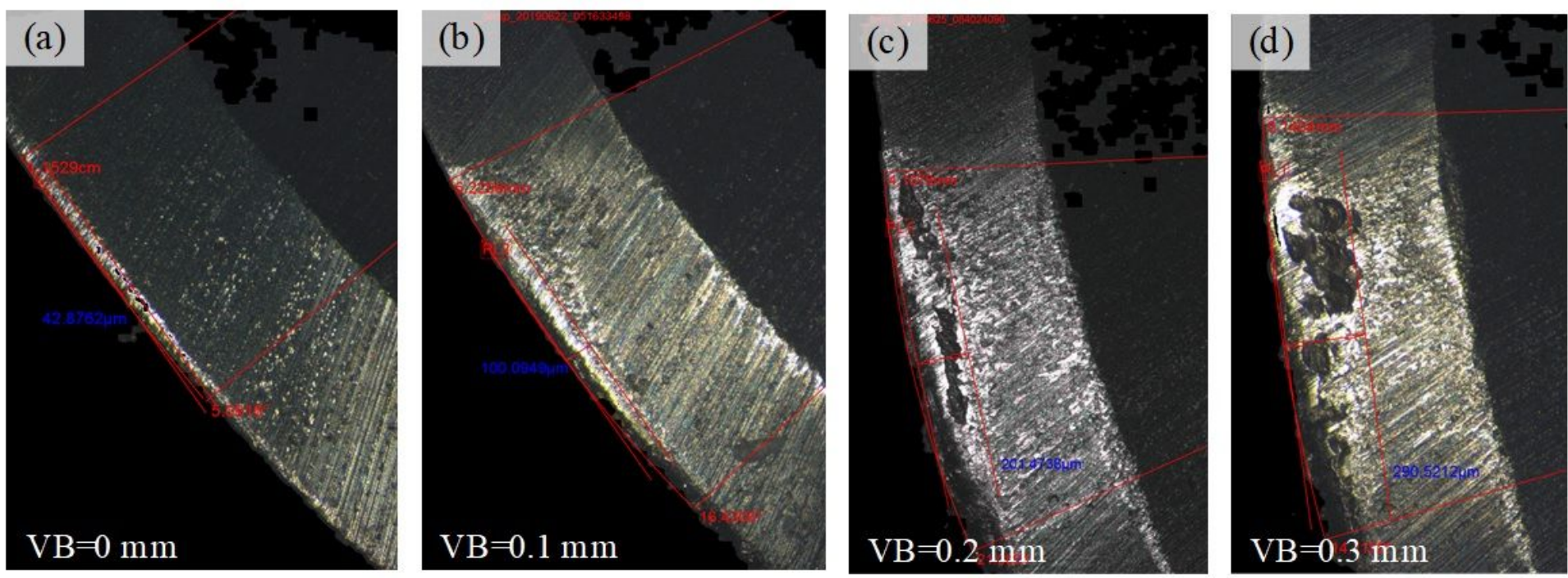

\section{Figure 4}

Tool wear morphology of ball nose end mill for a (a) new flank face, (b) VB=0.1 mm, (c) VB=0.2 mm, and (d) $\mathrm{VB}=0.3 \mathrm{~mm}$. 


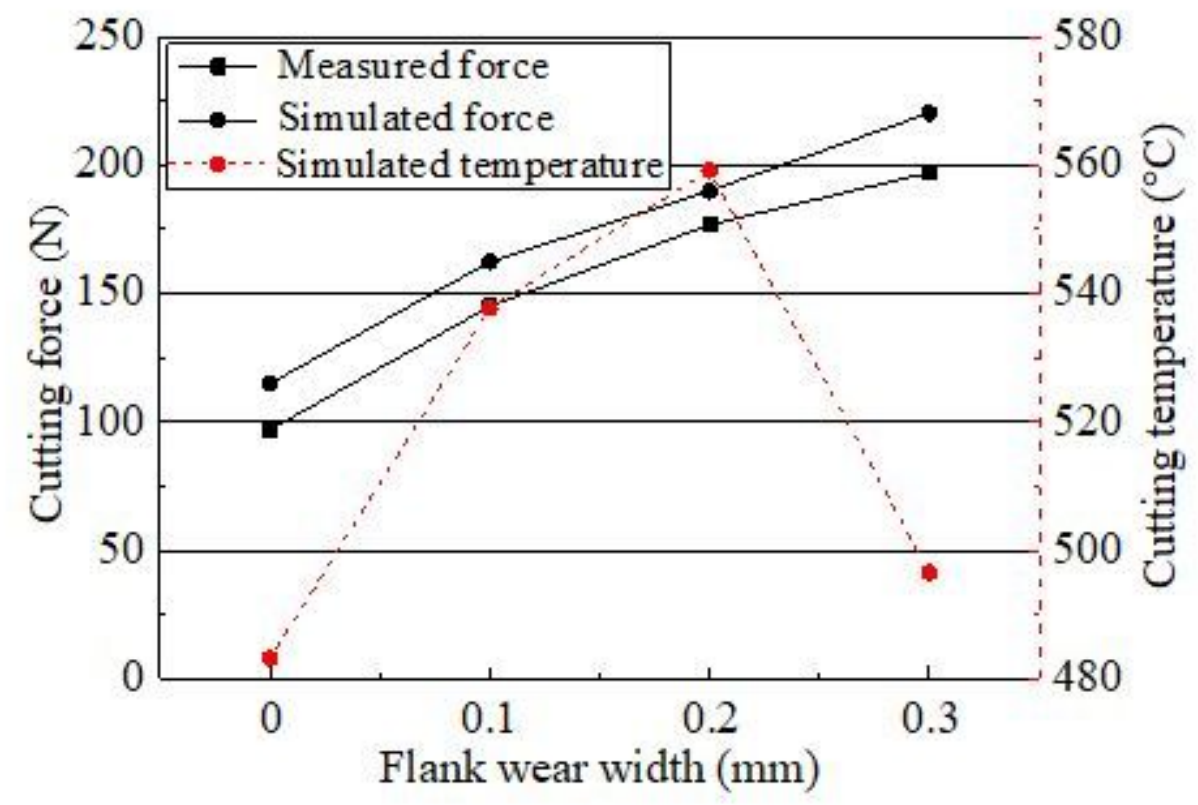

Figure 5

Comparison of the maximum cutting force and temperature under various tool flank wear widths.

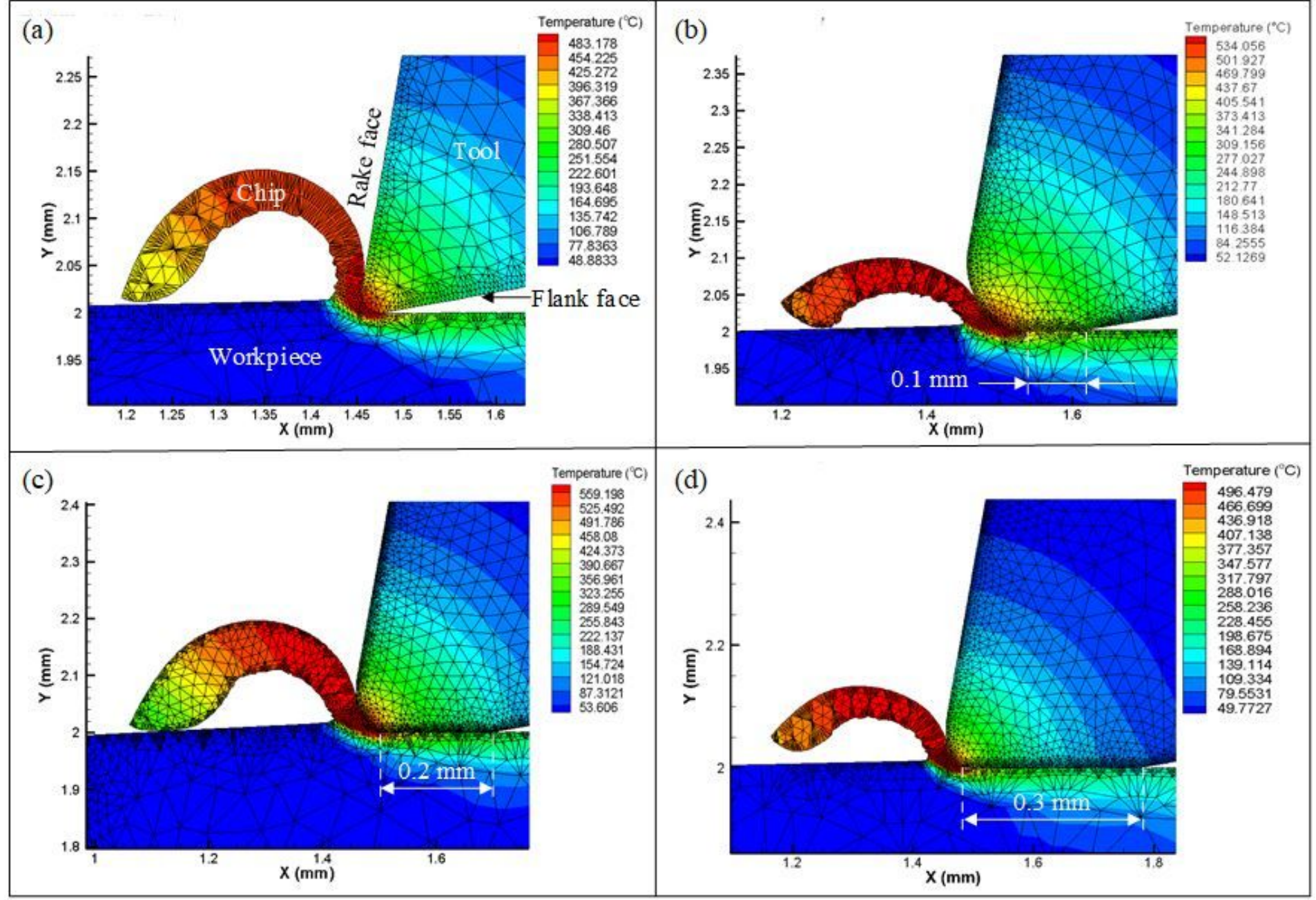


Figure 6

Cutting temperature distribution of workpiece-tool-chip interface for different tool flank wear widths of (a) $0 \mathrm{~mm}$, (b) $0.1 \mathrm{~mm}$, (c) $0.2 \mathrm{~mm}$, and (d) $0.3 \mathrm{~mm}$.

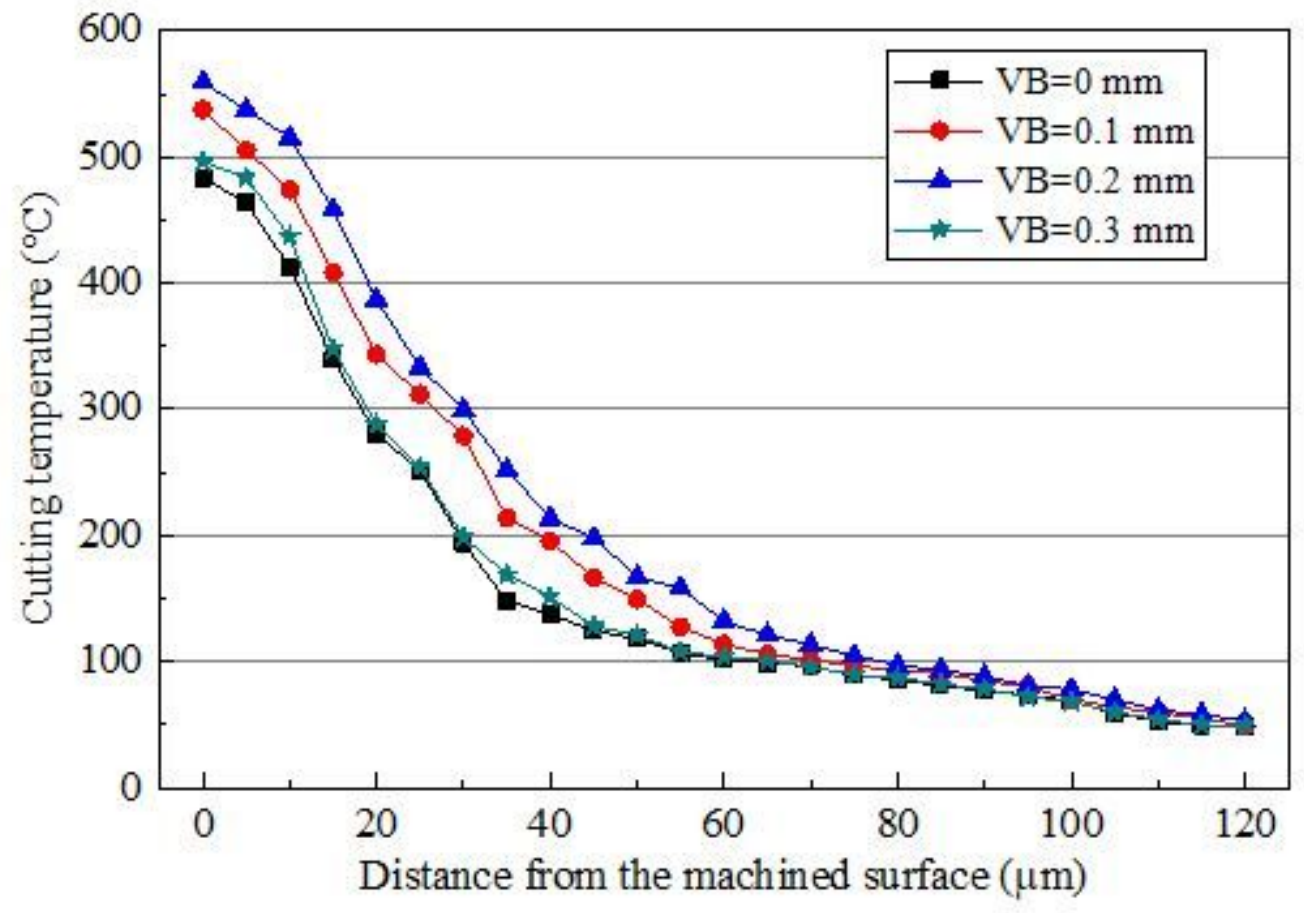

Figure 7

In-depth cutting temperature distribution for different tool flank wear widths. 


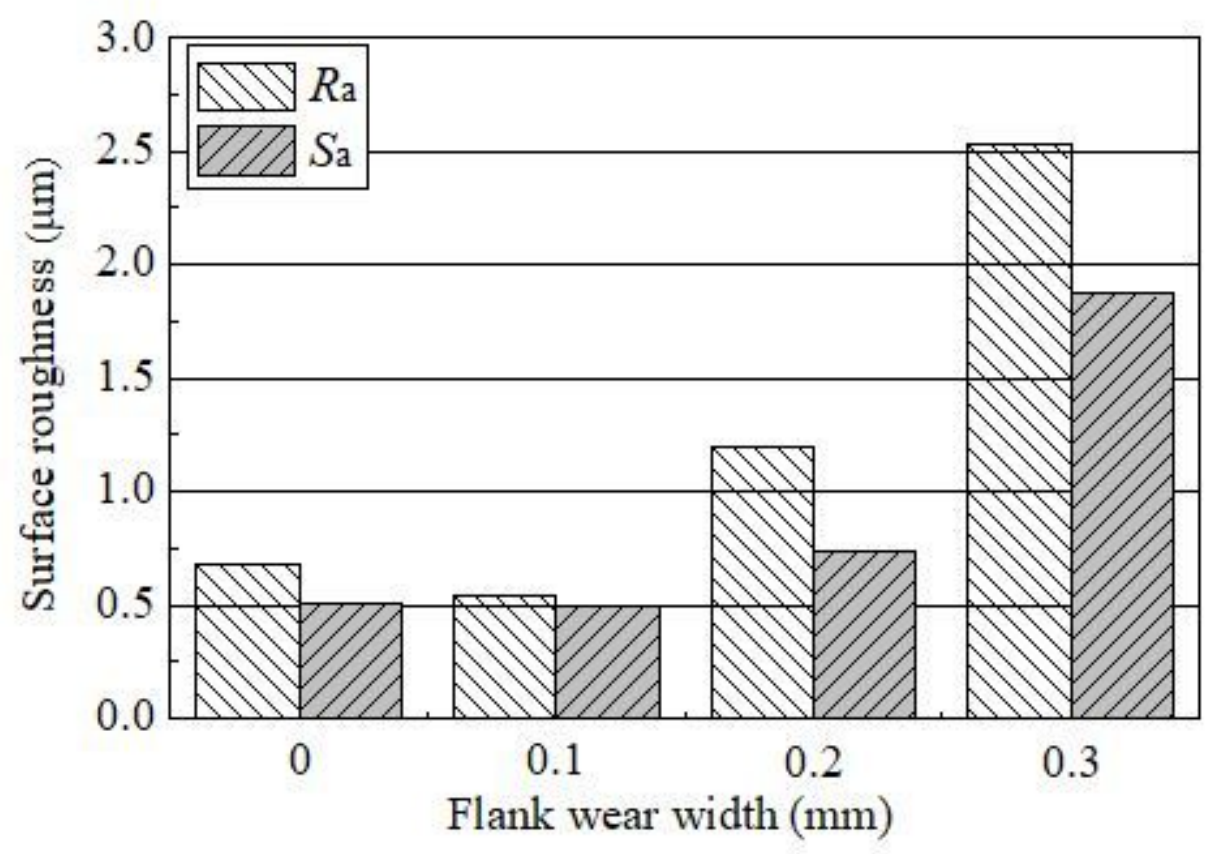

Figure 8

Effect of flank wear on surface roughness.

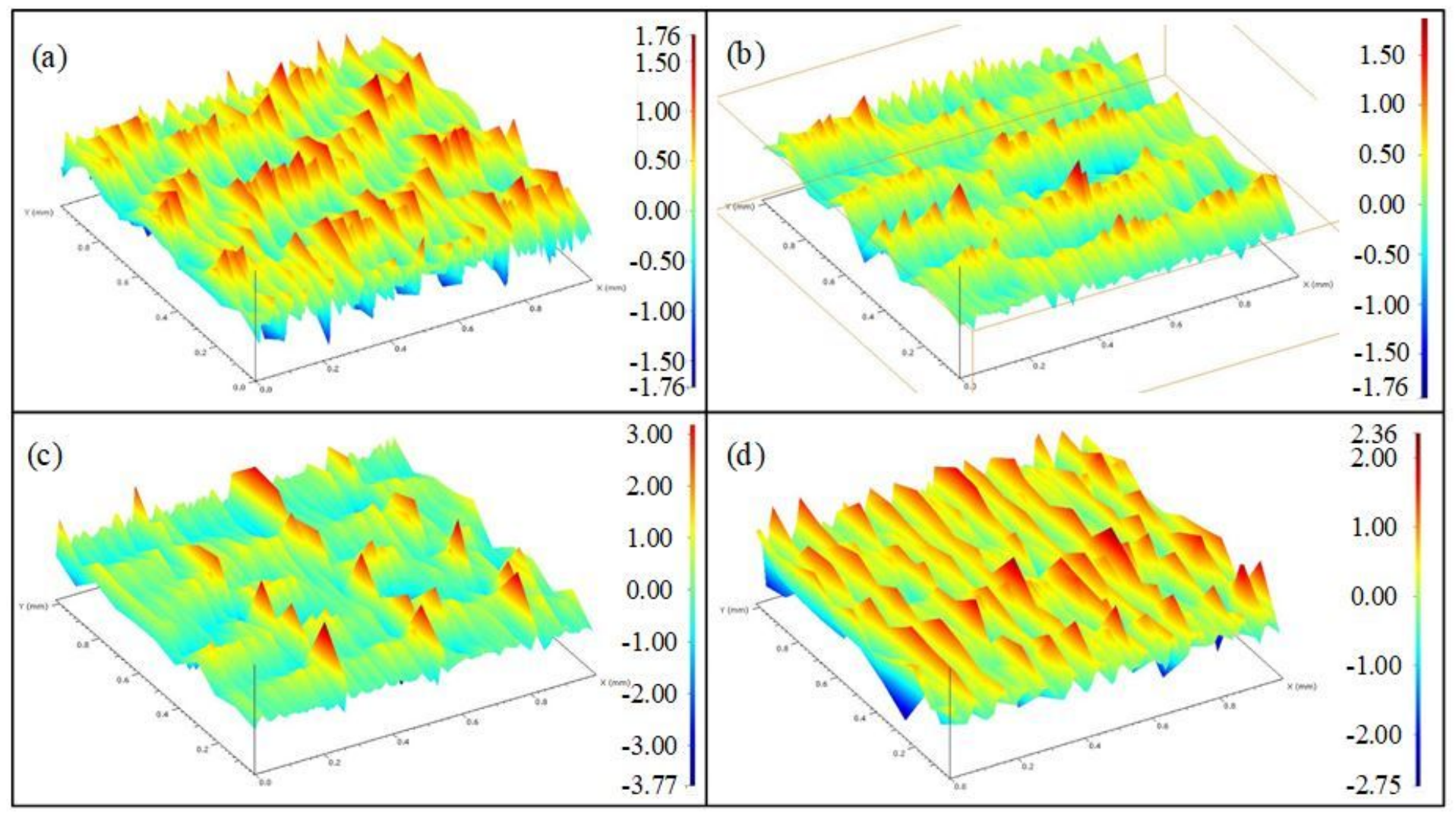

Figure 9 
Surface topographies for different tool flank wear widths of (a) $0 \mathrm{~mm}$, (b) $0.1 \mathrm{~mm}$, (c) $0.2 \mathrm{~mm}$, and (d) 0.3 $\mathrm{mm}$.
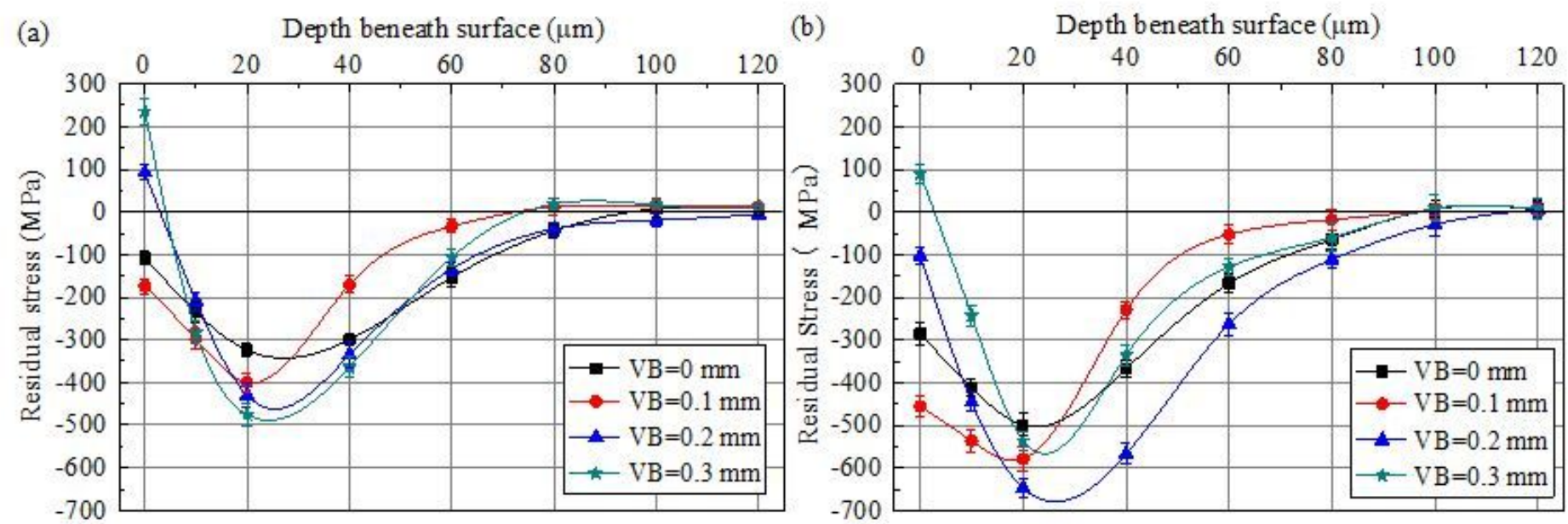

\section{Figure 10}

In-depth residual stress distributions for different tool flank wear widths along the (a) feed and (b) pick feed directions.
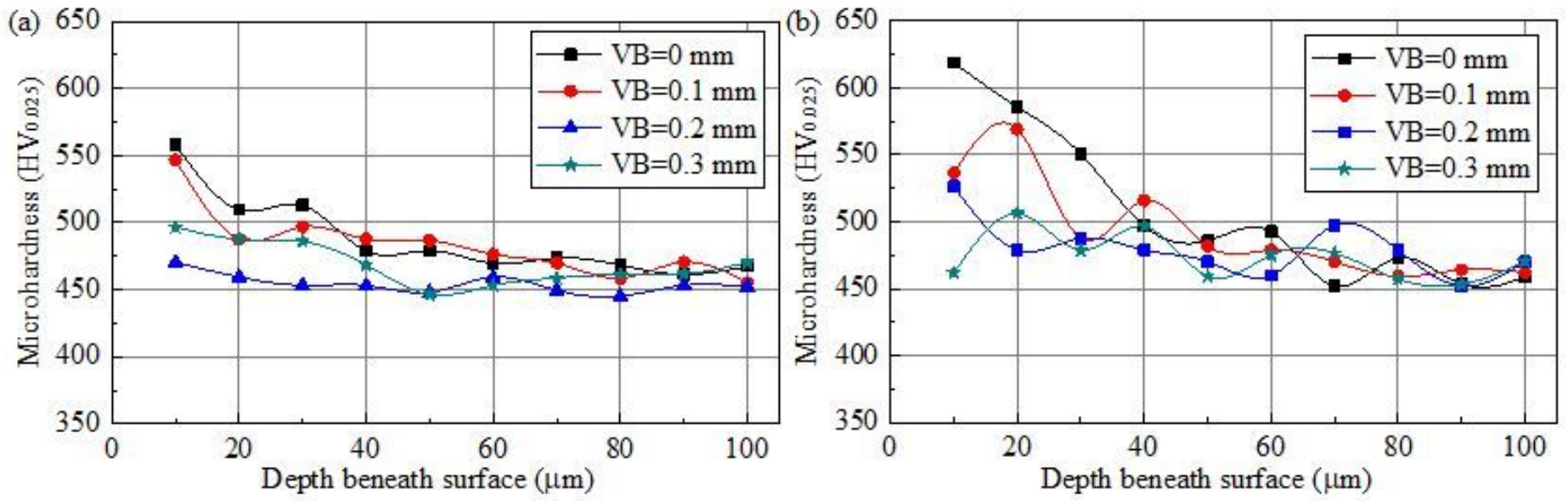

\section{Figure 11}

In-depth microhardness distributions for different tool flank wear widths along the (a) feed and (b) pick feed directions. 


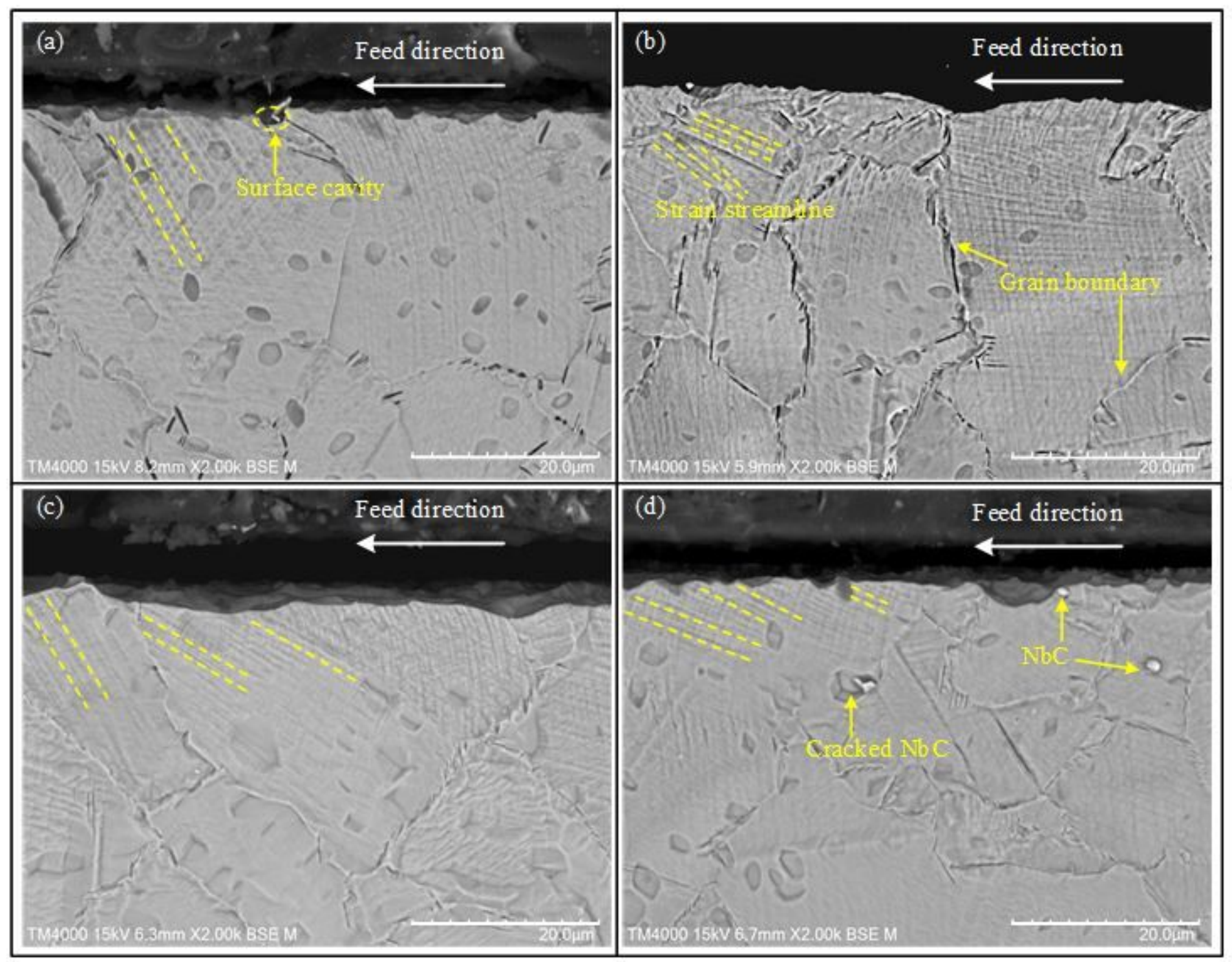

Figure 12

Microstructure of Inconel 718 for different tool flank wear widths of (a) $0 \mathrm{~mm}$, (b) $0.1 \mathrm{~mm}$, (c) $0.2 \mathrm{~mm}$, and (d) $0.3 \mathrm{~mm}$. 